\title{
Influence of Precipitation and Grain Size on the Hot Ductility of Alloy C-276 ESR Ingots
}

\author{
T.K. Kim, J. Jang, W.S. Ryu, J.H. Hong and A. Mitchell* \\ Korea Atomic Energy Research Institute, Nuclear Materials Technology Development Team \\ P.O. Box 105, Yusong, Taejon, 305-600 South Korea \\ *Department of Metals and Materials Engineering, University of British Columbia, Vancouver, B.C., Canada, V6T IZ4
}

(Received October 12, 2000)

\begin{abstract}
The influence of precipitation and grain size on the hot ductility of alloy C-276 ESR ingots has been determined. Tensile tests were performed in the temperature range of 950 to $1200^{\circ} \mathrm{C}$ at a strain rate of $6.1 / \mathrm{sec}$. The precipitation of the $P$ phase in this alloy revealed a detrimental influence on the hot ductility, because these precipitates tend to fracture prior to grain boundary sliding and dynamic recrystallization during deformation, and hence favor a low ductility cleavage fracture. Isolating the influence of precipitation from that of solution treatment for 2 hours showed that a considerable dissolution of the precipitates induced a significant improvement in the hot ductility, giving the mechanism for grain boundary sliding and dynamic recrystallization during deformation. Hot ductility drops at 1050 and $1200^{\circ} \mathrm{C}$ are attributed to the precipitation reprecipitated especially at grain boundary before deformation and grain boundary weakening at high temperatures, respectively. However, the worst hot ductility occurred when the solution of precipitates and grain growth were generated and the precipitates were reformed again in a fine form especially at the grain boundaries before deformation at intermediate temperatures.
\end{abstract}

\section{INTRODUCTION}

The effects of metallurgical factors, like grain size, precipitates, impurity elements and strain rate, on hot ductility in steels have been extensively studied /1-8/. While the smaller grain size in some steels increases the ductility /1-3/, austenite grain sizes in C-Mn-Al and CMn-Al-Nb steels do not affect the hot ductility /9/. For the influence of precipitates, the hot ductility of microalloy steels appeared to be dependent on the precipitation morphology and precipitate distributions which were in a coarse randomly precipitated form that gave improved hot ductility over those in a fine form $12 \%$. On the other hand, sulfur segregation and sulphide precipitation at the grain boundary have a deterimental influence on the hot ductility of low carbon steel /8/.

However, for alloy C-276, which is a structural material in the chemical and petrochemical industries due to its excellent corrosion resistance along with good weldability /10-12/, there has been little indication from hot tensile tests that precipitation and grain size have any significant influence on hot ductility. This alloy usually exhibits working defects such as hot-cracking due to intermetallic and grain boundary precipitates in the time periods likely to be encountered in most hot working operations $/ 13 /$. It is therefore of commercial 
importance to establish the influence of solution treatment (ST) considered to improve the hot ductility in alloy $\mathrm{C}-276$.

The electroslag remelting (ESR) process has been widely used in the refining of Ni-based alloys and forging steels /14-18/. This process has positive effects in improving hot ductility transverse to the rolling or forging direction. The adoption of the ESR process thus ought to be very effective in achieving both the exclusion of the influence of sulfur on hot ductility and also on improving hot ductility through the control of grain growth $/ 19 /$.

The purpose of this study is to determine the influence of precipitation and grain size on the hot ductility of ESR alloy C-276, and to establish the importance of the influence of the two factors outlined above. The dissolution of the precipitates and the variation in grain size for the alloy examined has been principally achieved by solution treatment.

\section{EXPERIMENTAL PROCEDURE}

Alloy C-276 electrodes prepared by vacuum induction melting were electroslag remelted. A ternary flux system of (wt. \%) $70 \mathrm{CaF}_{2}-15 \mathrm{Al}_{2} \mathrm{O}_{3}-15 \mathrm{CaO}$ was used as a refining agent to enhance the desulfurization reaction $/ 14 /$, and a deoxidant with a composition of (wt. \%) Ni-15Mg was continuously added to the slag bath for slag deoxidation during the remelting process 120-22/. The chemical composition of the ESR ingot studied is given in Table 1 . The ingot was solution treated at a temperature of $1250^{\circ} \mathrm{C}$ for 2 hours (ST-2), and also for 5 hours (ST-5).

Hot tensile specimens with a gauge length of 120 $\mathrm{mm}$ and a diameter of $8 \mathrm{~mm}$ were prepared from the columnar crystal zones in a direction parallel to the cylindrical ingot. Tests were carried out at six different temperatures, ranging from 950 to $1200^{\circ} \mathrm{C}$. The test specimens were induction heated at a rate of $5^{\circ} \mathrm{C} / \mathrm{sec}$ to the test temperature in an argon atmosphere and held for 3 minutes. Isothermal tensile testings were carried out at a strain rate of $6.1 / \mathrm{sec}$, equivalent to hot working condition. Microstructures with the same thermal history were examined prior to deformation using separate specimens.

The morphology and area fraction of the precipitates in the samples, before and after solution treatment, were examined using a scanning electron microscope (SEM) and image analyzer (IA). Carbon extraction replicas of the precipitates taken from samples were examined using a transmission electron microscope (TEM) and energy dispersive spectroscope (EDS). The fractured surfaces and longitudinal sections of the samples tested were also examined.

\section{RESULTS}

\subsection{Precipitate and grain size before testing}

The second phase particles in the as-cast and ST-2 samples before testing at a test temperature of $1050{ }^{\circ} \mathrm{C}$ are shown in Figure 1. The second phase particles before and after solution treatment showed quite a different morphology. The precipitates in the as-cast sample showed a morphology which combined several small particles, and this shape possibly indicates that precipitation took place in the interdendritic region. In contrast, the precipitates in the solution treated sample have a spherical morphology. With respect to the size of the particles, there was a significant change from approximately $20 \mu \mathrm{m}$ in the as-cast sample to

Table 1

Chemical Composition of the ESR Ingot of Alloy C-276

\begin{tabular}{lccccccccccccc}
\hline & $\mathrm{Ni}$ & $\mathrm{Fe}$ & $\mathrm{Mn}$ & $\mathrm{C}^{\sharp}$ & $\mathrm{Si}$ & $\mathrm{S}^{\#}$ & $\mathrm{Cr}$ & $\mathrm{Mo}$ & $\mathrm{P}^{\sharp}$ & $\mathrm{W}$ & $\mathrm{Co}$ & $\mathrm{O}^{\#}$ & $\mathrm{~N}^{\#}$ \\
\hline \multirow{2}{*}{ ESR ngot } & $\mathrm{Bal}$. & 5.00 & 0.34 & 70 & 0.06 & $<10$ & 15.1 & 16.9 & 70 & 3.80 & 0.20 & 38 & 56 \\
\hline
\end{tabular}

\# ppm unit, others are wt. pct. 


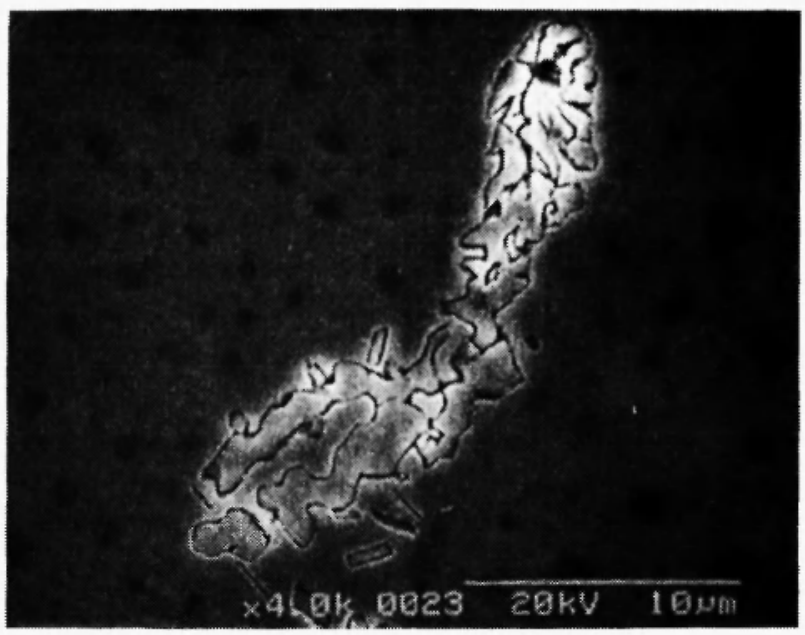

(a)

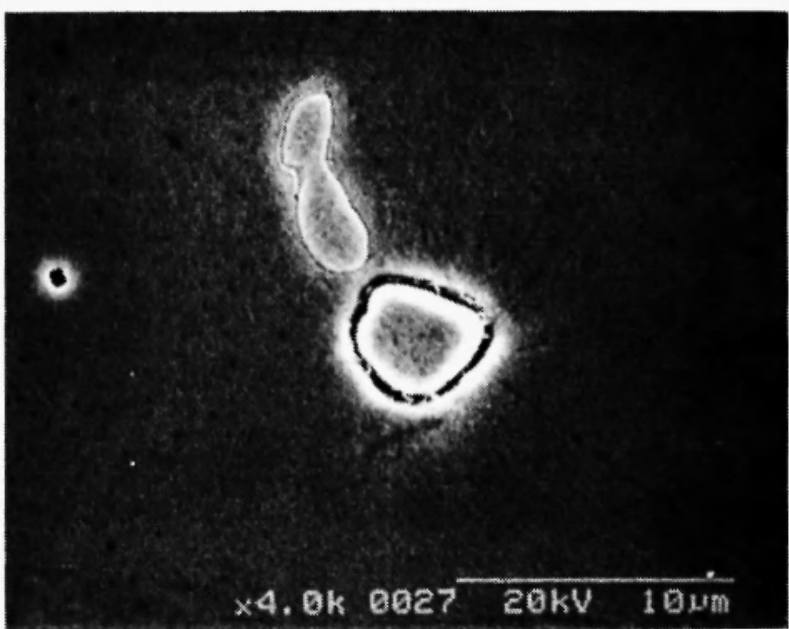

(b)

Fig. 1: The second phase particles in the (a) as-cast and (b) solution treated samples before testing at $1050^{\circ} \mathrm{C}$

approximately $5 \mu \mathrm{m}$ in the ST- 2 sample.

Figure 2 shows the influence of ST and test temperature on the area fraction of the precipitates in the as-cast and ST samples. The amount of precipitates in the ST samples was much smaller than that of the precipitates in the as-cast samples, and only a slight difference in the amount of particles in the ST samples for 2 and 5 hours was observed. In addition, the area fraction of the precipitates in all samples increased at

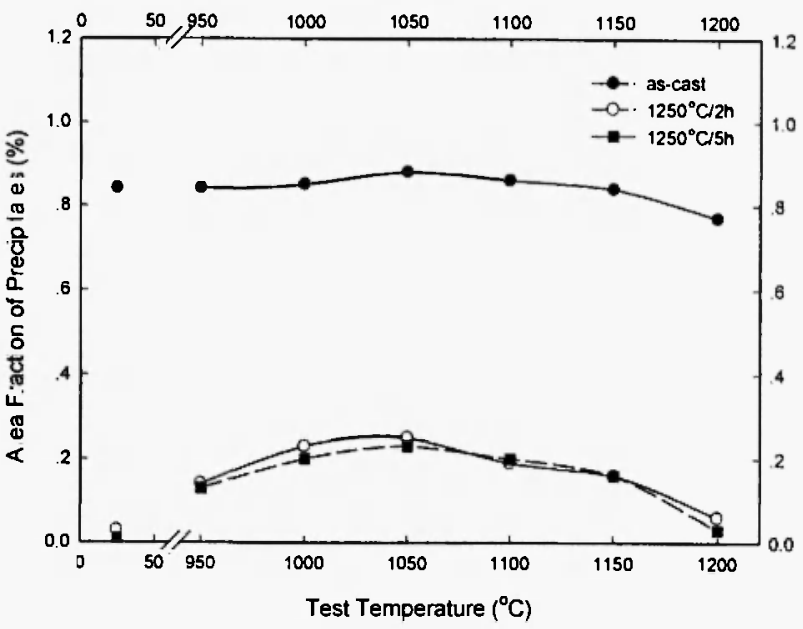

Fig. 2: The influence of solution treatment and test temperature on the area fraction of precipitates in the transverse sections of alloy C-276 ESR ingot.

the test temperatures compared with those of the precipitates before heating for testing. Before testing at $1200^{\circ} \mathrm{C}$, the volume of precipitates in the samples appeared to be slightly reduced. It should be noted that for all samples, especially for ST samples, the area fraction of precipitates at the test temperatures of $1050^{\circ} \mathrm{C}$ was somewhat larger than those at the other temperatures.

An examination of the carbon extraction replicas taken from the as-cast samples showed that most of the precipitates were a Mo-rich precipitation of $P$ phase (Figure 3). The average composition was determined to be (wt.\%) $28.0 \mathrm{Ni}, 45.9 \mathrm{Mo}, 13.6 \mathrm{Cr}, 9.4 \mathrm{~W}$, and $3.0 \mathrm{Fe}$. The $P$ phase precipitate (orthorhombic, $a=0.907 \mathrm{~nm}, b$ $=1.698 \mathrm{~nm}, \mathrm{c}=0.475 \mathrm{~nm})$ is an intermetallic topologically close-packed (TCP) phase with a chemical formulation of $\mathrm{Cr}_{9} \mathrm{Mo}_{21} \mathrm{Ni}_{20}$. This phase in the $\mathrm{Ni}-\mathrm{Cr}-$ Mo alloy system was originally defined by Shoemaker et al. 123\%. No $\mu$ phase, which would possibly be present in these samples when aged for long time, was observed. After solution treating for 2 and 5 hours at $1250^{\circ} \mathrm{C}$, most of the precipitates were dissolved into the matrix. However, replicas taken from the samples before testing at test temperatures revealed a small amount of $P$ phase precipitation again, mostly in the matrix, but occasionally at the grain boundaries. This 


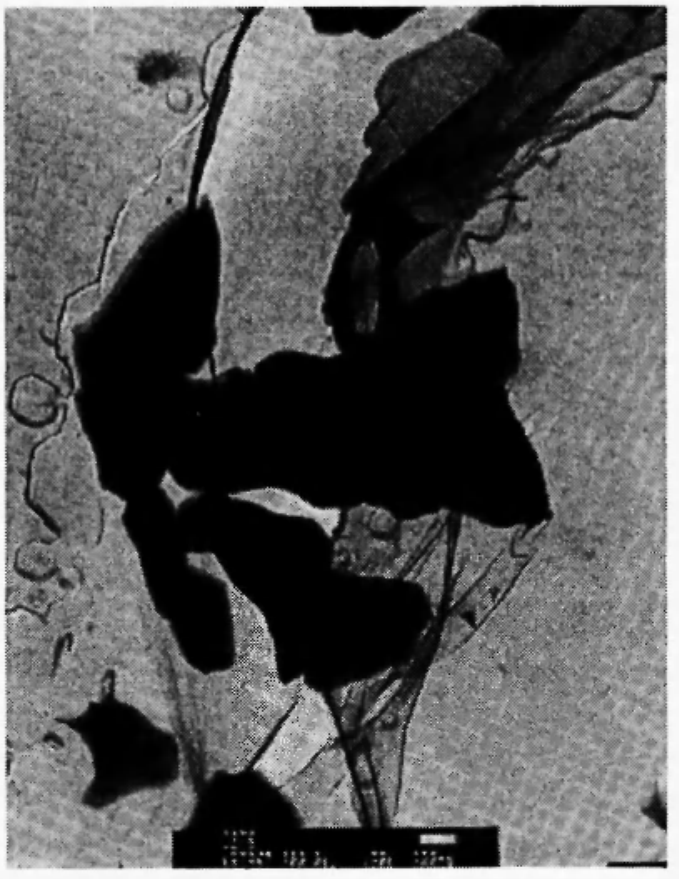

(a)

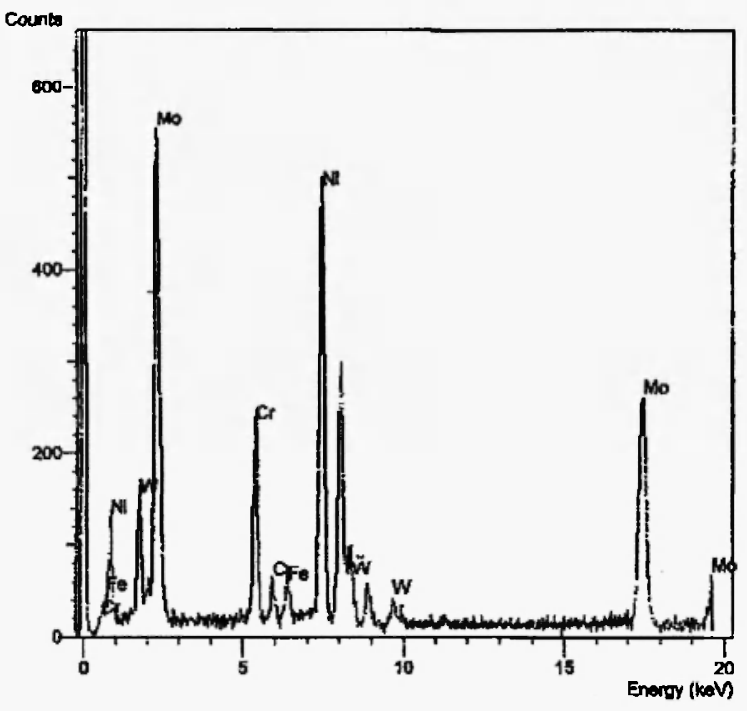

(b)

Fig. 3: (a) Extraction replica electron micrograph of $P$ phase in the ESR ingot of alloy C-276, and (b) EDS spectrum from the $P$ phase.

observation means that the particles were reprecipitated before testing at the test temperatures. These precipitates showed a spherical shape in a fine form with an average size of $5 \mu \mathrm{m}$, as shown in Figure $1 \mathrm{~b}$.
Figure 4 shows the influence of ST and test temperature on grain size in the transverse sections of the ESR ingot of alloy C-276. The grain size increased by solution treatment i.e from $345 \mu \mathrm{m}$ in the as-cast sample to $455 \mu \mathrm{m}$ in the ST-2 sample, and further up to $587 \mu \mathrm{m}$ in the ST-5 sample. There was no marked increase in grain size after hot tensile test.

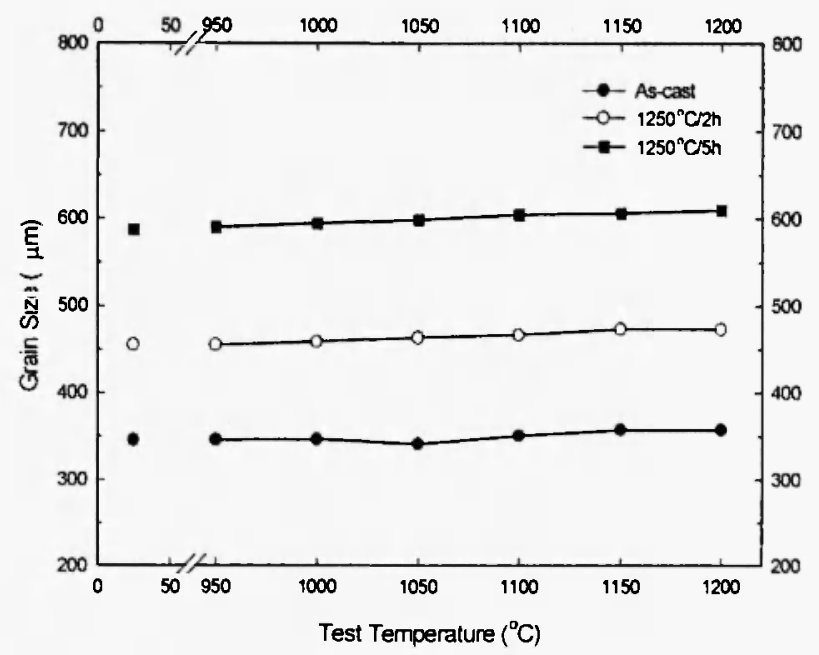

Fig. 4: The influence of solution treatment and test temperature on the grain size in the transverse sections of alloy C-276 ESR ingot.

\subsection{Hot ductility}

The influence of precipitation and grain size on the hot ductility of ESR ingot is shown in Figure 5. The ascast samples showed average RA values of $42 \%$ with little variation at all test temperatures. There was a significant improvement in the ST-2 samples at all test temperatures. This means that a dissolution of the precipitates induced a considerable improvement in hot ductility of alloy C-276. It is also observed that there are hot ductility drops at the temperatures of 1050 and $1200^{\circ} \mathrm{C}$.

On the other hand, the variation of RA values with temperature in the ST-5 samples has a similar characteristic to that of the temperature variation of RA values in the ST-2 samples. Compared with the RA values of the ST- 2 samples, the ST- 5 samples revealed relatively similar levels at temperatures of 950,1000 , 1150 and $1200^{\circ} \mathrm{C}$. There were also hot ductility 


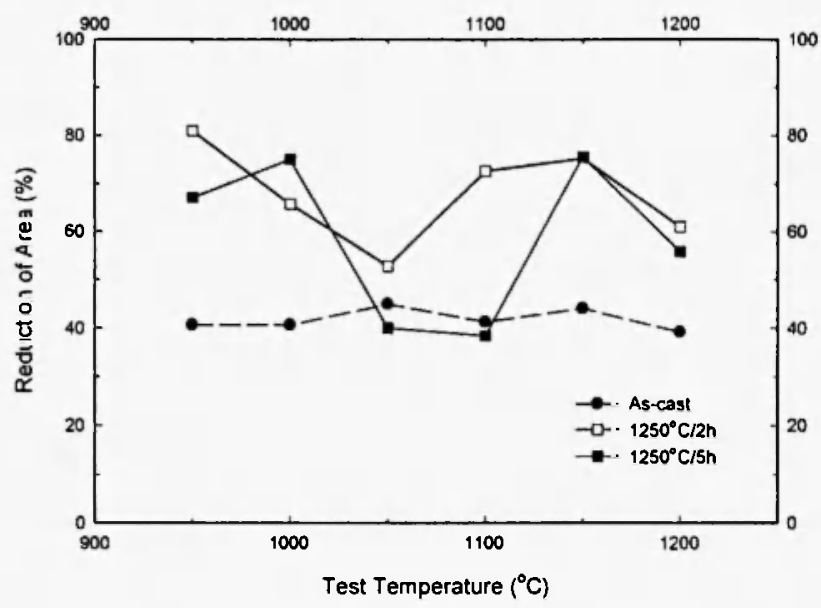

Fig. 5: Influence of solution treatment for 2 and 5 hours on the hot ductility of as-cast ESR ingot of alloy C-276.

decreases at 1050 and $1100^{\circ} \mathrm{C}$. This implies that the grain size has little influence on hot ductility. The variation of RA values with temperature observed in the ST-2 samples was independent of grain size. However, it should be noticed that hot ductility decreases for the ST-5 samples at $1050^{\circ} \mathrm{C}$ were more severe than those for the ST-2 ones, and the temperature range of hot ductility decrease was expanded into the region of $1100^{\circ} \mathrm{C}$

Examination of the fractured surfaces of these samples using SEM revealed three distinct fracture modes: cleavage mode with flat facet (Figure 6),

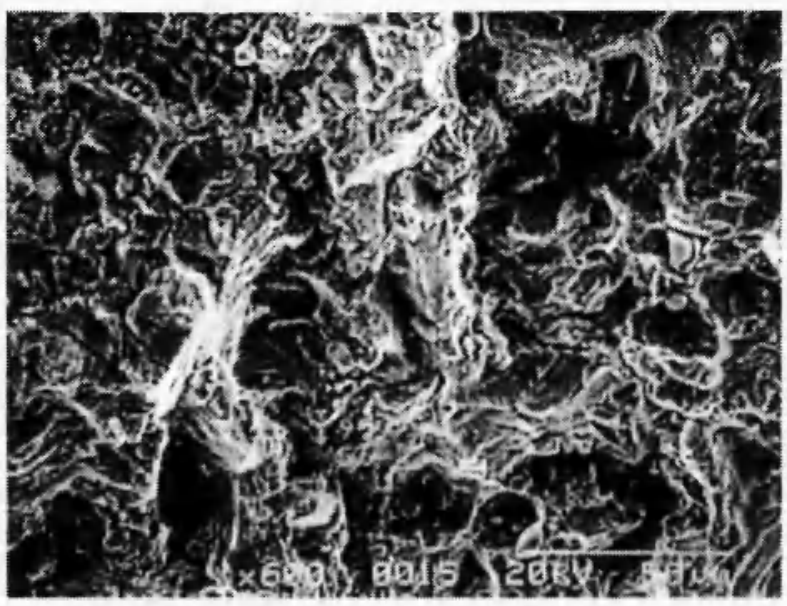

Fig. 6: Fracture surface of sample with RA value of less than $55 \%$, showing brittle fracture. microvoid coalescent (Figure 7) and transgranular ductile failure (Figure 8 ). The cleavage fracture in Figure 6, representing the brittle fracture, can be found in the fracture samples with RA values of less than $55 \%$. The fracture appeared to occur in the matrix, because it is possible to observe that precipitates within the grain remain in the cavities and there is a little intergranular decohesion. Figure 9 shows an SEM image taken in the vicinity of the longitudinal section of the as-cast sample tested at $1150^{\circ} \mathrm{C}$. It can be observed

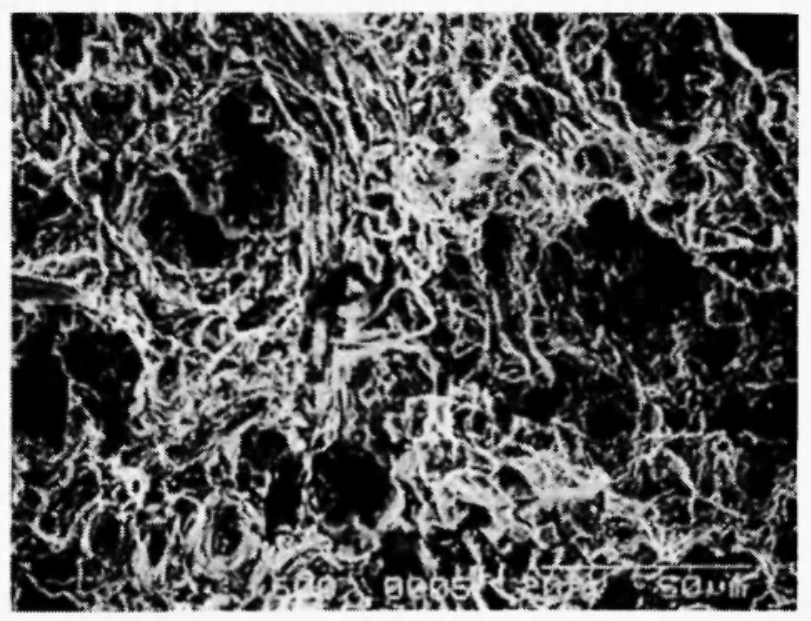

Fig. 7: Fracture surface of sample with RA value of about $70 \%$ at test temperatures of over than $1100^{\circ} \mathrm{C}$, showing microvoid coalescent fracture.

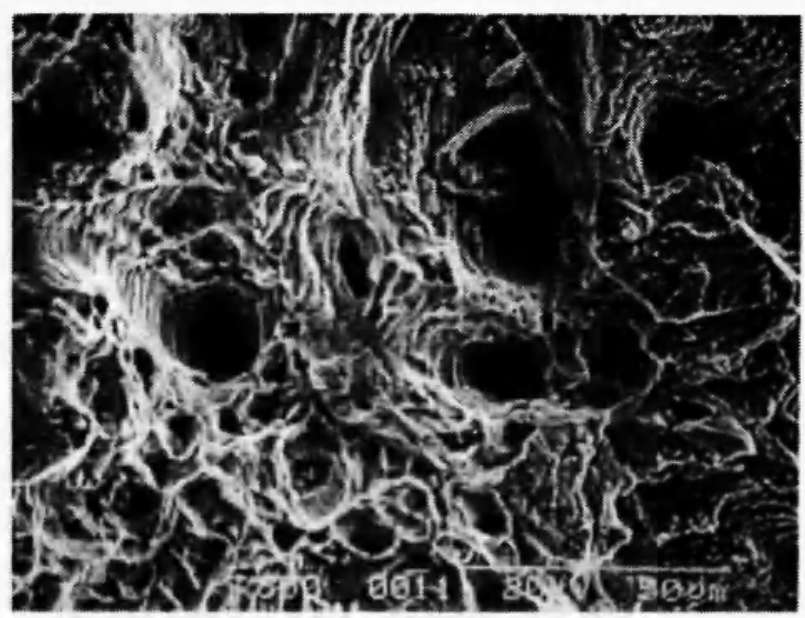

Fig. 8: Fracture surface of sample with high RA value of over than $70 \%$ at test temperatures of less than $1000^{\circ} \mathrm{C}$, showing ductile fracture. 


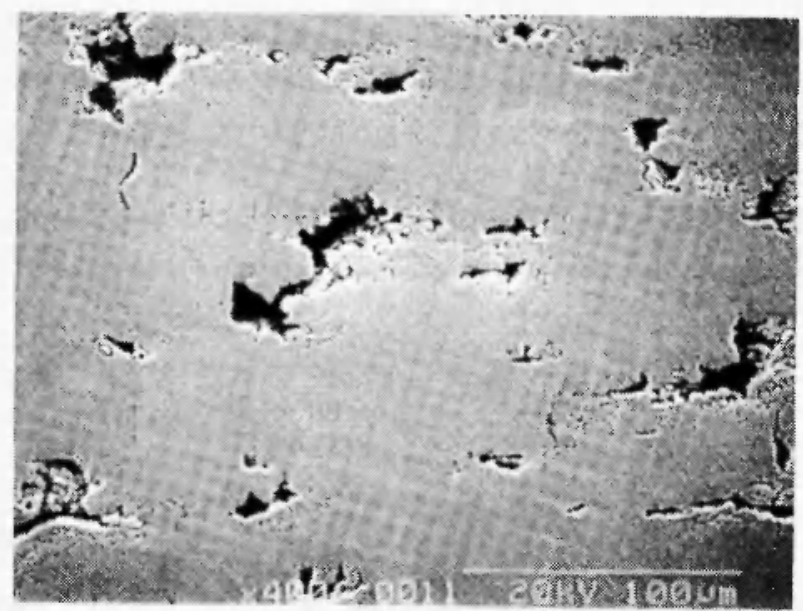

Fig. 9: SEM micrograph in the vicinity of the longitudinal section of the as-cast sample tested at $1050^{\circ} \mathrm{C}$.

that fracture is intimately associated with second phase precipitates, because most cracks originated at the precipitates within the grains during deformation. Thus, it can be concluded that numerous precipitates are responsible for low ductility, giving the cleavage fracture mode.

In Figure 7, these fractures are observed in the fracture samples with RA values of about $60-70 \%$ at high temperatures over $1100^{\circ} \mathrm{C}$. It is observed that the fracture surface consists of microvoids on the grains with some dimples, characteristic of precipitationcontrolled failure. Figure 10 shows the microstructure in the vicinity of the longitudinal section of the ST-2 sample tested at $1150^{\circ} \mathrm{C}$. It can be seen that dynamic recrystallization beside the as-cast grain boundary occurred during deformation, and this is partly associated with second-phase particles. It is concluded that the microvoids result from finely dispered precipitates re-formed before deformation.

In Figure 8, illustrating the ductile rupture, large voids are apparent on the fracture surface. This type of fracture is invariably associated with a high RA of over $70 \%$ at test temperatures below $1000^{\circ} \mathrm{C}$. The large voids are originally intergranular cracks formed by grain boundary sliding at an early stage of deformation. As deformation proceeds, the original grain boundary crack is distorted into an elongated void, until final failure occurs by necking between the voids. Figure 11 shows

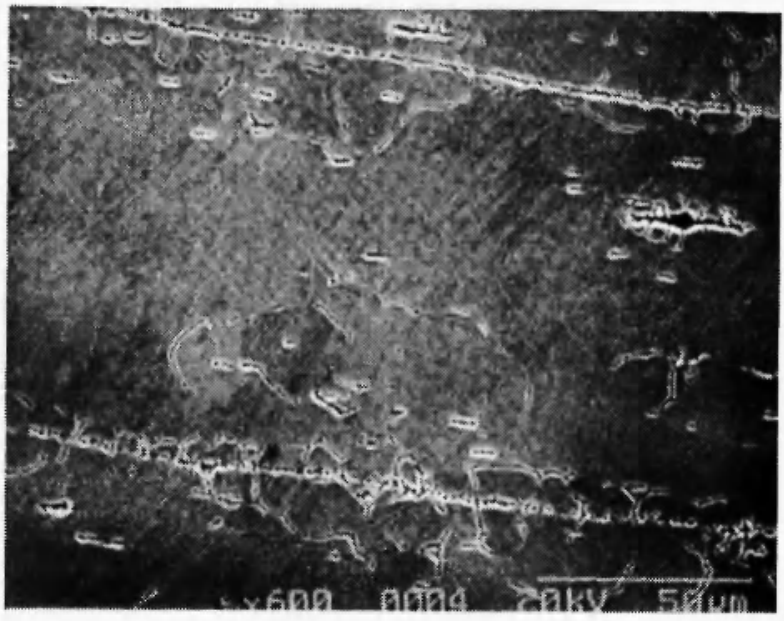

Fig. 10: Microstructure in the vicinity of the longitudinal section of the ST-2 sample tested at $1150^{\circ} \mathrm{C}$, showing dynamic recrystallization beside of the as-cast grain boundary.

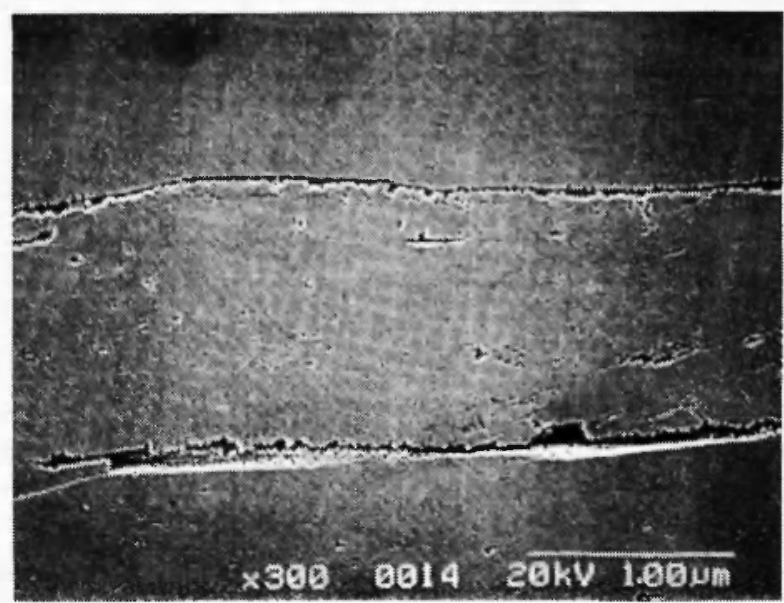

Fig. 11: Microstructure in the vicinity of the longitudinal section of the ST-2 sample tested at $950^{\circ} \mathrm{C}$, showing the grain boundary sliding.

an SEM image in the vicinity of the longitudinal section of the ST-2 sample tested at $950^{\circ} \mathrm{C}$. Fracture does not appear to be associated with second-phase particles, since grain boundary sliding appears to occur during deformation. In addition, there is no evidence of dynamic recrystallization.

\section{DISCUSSION}

There are three important factors which have 
significant effects on hot ductility: sulfur content, grain size and precipitates. Sulfur as an impurity has a detrimental influence on the hot ductility through sulfide size and morphology in low carbon steels /8/. High purity alloy C-276 strongly de-sulphurised by the ESR process would be expected to remove completely the detrimental influence of sulfur on hot ductility, because this alloy in the present study contains a low sulfur content of less than $10 \mathrm{ppm}$, and a residual magnesium content greater than $2.5 \times \mathrm{S} \%$ (Table 1 ), which is the usual criterion for removing the sulphur effect in nickel-based alloys.

\subsection{Interpretation of precipitation in alloy C-276}

The phase identification of precipitates in alloy $\mathrm{C}$ 276 has been extensively discussed and indicate that this alloy contains $\mathrm{P}$ and $\mu$ phases (defined by Beattie and Hagel in the Ni-Cr-Mo alloy system /24/). In the present study, most of the precipitates found in the as-cast ESR ingots of alloy C-276 were identified as a Mo-rich P phase (Figure 3 ). These analytical results coincide well with the other results on phase identification in alloy C$276 / 11,25-30 /$. Besides the $\mathrm{P}$ phase, the precipitation of a TCP phase, $\mu$, has also been observed in this alloy when aged $/ 26,27 /$. In alloy $\mathrm{C}-276$, it has been reported that the $\mu$ phase is a long-time transformation product of the $P$ phase in the temperature range of 649 to $1093^{\circ} \mathrm{C}$ $/ 11,25 /$. The ESR process gives relatively high temperature gradient/solidification rate to the liquid metal region, which gives a small value for the local solidification time. In particular, the ESR furnace of the experimental scale $(75 \mathrm{~mm}$ inner diameter) would be more effective in this respect. During solidification, a very short local solidification time upon cooling to room temperature would not allow the complete transformation of the $\mathrm{P}$ phase to the other TCP phase, $\mu$.

The mechanism that alloy $\mathrm{C}-276$ contains $P$ phase precipitation during remelting could be explained in terms of the crystal structures of the main alloy components. During the solidifying stage, whereas $\mathrm{Ni}$ and $\mathrm{Fe}$ have face-centered-cubic (fcc) crystal structures and become the main components of the fcc $\gamma$ matrix, Mo and $W$, which have body-centered-cubic (bcc) structures, would tend to destabilize the fcc $\gamma$ matrix and then become main components to form a precipitate in the interdendritic regions and at the grain boundaries.

For the transverse section of the as-cast ESR ingot, the precipitates in the interdendritic region have morphologies as shown in Figure la. During heat treatment, these precipitates diffuse into the matrix as the degeneration reactions of the precipitates occur. After solution treatment for 2 hours, the equilibrium $\gamma$ matrix has been almost fully stabilised as a result of the dissolution of the precipitates.

However, examination using a SEM on the samples immediately before testing at the test temperatures indicates that precipitates are re-formed in a small size range with an average size of $5 \mu \mathrm{m}$ (Figure $\mathrm{lb}$ ). This implies that a heating rate of $5^{\circ} \mathrm{C} / \mathrm{sec}$ up to the test temperature and a holding period of 3 minutes could be responsible for re-forming the precipitates in those test samples. It is thus considered that there is a driving force to reprecipitate the particles in alloy C-276 ESR material, and the driving force at $1050^{\circ} \mathrm{C}$ is stronger than that at the other temperatures because the area fraction of the precipitates reprecipitated at this temperature shows the largest value of all the test temperatures. The morphologies of the precipitates in the ST-2 sample (Figure lb) can then be explained in terms of interfacial energy. The precipitation would tend to decrease the $\gamma / \mathrm{P}$ interfacial energy to as low as possible so as to achieve stablization of precipitation after it has been reformed during the time periods of heating up to test temperature and holding for 3 minutes, which explains the spherical morphology of precipitation. The size of precipitates reprecipitated would be dependent on the time periods of heating and holding the samples before testing.

\subsection{Influence of precipitation on the hot ductility}

The as-cast ESR ingots of alloy C-276 showed RA values in about a $40 \%$ range, which is an insufficient level of hot ductility for hot working processes. These low ductility values are closely associated with the precipitation of $P$ phase. As the examination reflects embrittling and weakening properties on the precipitates during hot deformation (Figure 9), the precipitates would have brittle and fragile properties in the presence 
of stress at high temperatures. The precipitate particles would be under enhanced strain localization during deformation. In addition, there would be an effect of $\gamma / \mathbf{P}$ interfacial tension depending on the $\gamma / P$ lattice mismatch, because $P$ would not be coherent with the matrix which has a fcc structure, as opposed to the $P$ precipitates which are octahedral. The $\gamma / \mathrm{P}$ interface would hence be weaker than the surrounding matrix during hot deformation, tending to fracture prior to the onset of grain boundary sliding (Figure 9). The lowductility cleavage and intergranular fracture mode observed in the as-cast sample tested at $1050^{\circ} \mathrm{C}$ is mainly attributed to the precipitates within the grains and in the grain boundaries, respectively (Figure 6). There was no evidence of dynamic recrystallization during deformation in the as-cast sample tested, even at $1050^{\circ} \mathrm{C}$ (Figure 9). It is considered that most of the fractures would occur due to embrittling and weakening of the precipitates prior to dynamic recrystallization.

Metallographic examination indicates that solution treatment at $1250^{\circ} \mathrm{C}$ was sufficient to dissolve a considerable amount of precipitates in the as-cast alloy (Figure 2). After solution treatment for 2 hours, almost complete precipitate dissolution has occurred and hence hot ductility was significantly improved. Solution treatment produces a region of precipitation depletion as a result of the precipitate degeneration reaction, which results in the production of an enhanced localized ductility zone. The precipitate depletion is accompanied by the elimination of the surface energy of the $\gamma / P$ interface. These effects promote the cross-slip of grains during grain movement, retarding the initiation of a fracture. Examination of the fracture surface demonstrates that the samples which mainly fractured by the influence of precipitates in the grain boundaries show RA values of less than $50 \%$ and low ductility intergranular failures, whereas the samples little affected by the precipitates during deformation showed RA values of over $60 \%$ and a high ductility fracture mode. These results were confirmed by a metallographic examination which showed that there was extensive grain boundary sliding in the sample tested at $950^{\circ} \mathrm{C}$ and dynamic recrystallization in the sample tested at $1150^{\circ} \mathrm{C}$ as a result of the elimination of precipitates principally at the grain boundaries (Figures 10 and 11).

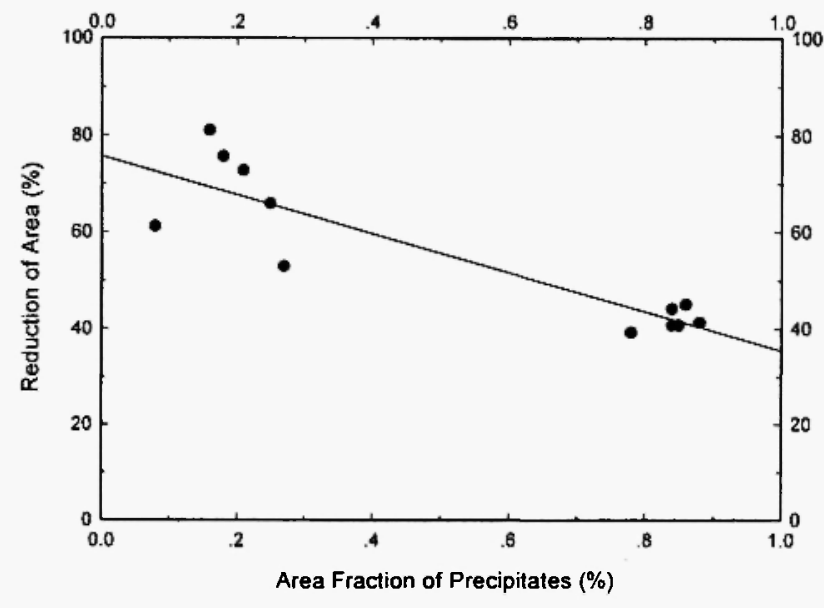

Fig. 12: The correlation of hot ductility and the area fraction of precipitate in alloy C-276 ESR ingot.

The correlation of hot ductility and the area fraction of precipitates in alloy C-276 ESR ingots in the temperature range of 950 to $1200^{\circ} \mathrm{C}$ is shown in Figure 12. The RA values are strongly dependent on the area fraction of the precipitates, and decrease with increasing amounts of precipitates. These results indicate that the presence of precipitation is of fundamental importance in hot ductility, and that the extent of precipitation has a considerable influence on the hot deformation of alloy C-276 ESR materials. It is thus possible to predict that hot ductility would always be improved when the precipitates are absent, thus preventing fracture initiation and facilitating grain boundary sliding. The detrimental effects of precipitation on the hot ductility of alloy C-276 coincides with other results which indicate that the presence of certain TCP phases influences the mechanical properties of Ni-based alloys |31-34/.

An examination of the grain size before and after solution treatment for 2 hours showed that there was an enlargement of grain size (Figure 4), although in the early solution treatment stage the precipitates in the grain boundary act to restrict grain growth until they are completely dissolved into the matrix. However, based on these results, it is believed that the volume of precipitates would have a more important influence on the hot ductility than the precipitate morphology and grain size. 
There was a considerable change in the size and morphology of the precipitates before and after solution treatment (Figure 1). It has been shown that precipitate morphology has little influence in Co-based alloys $135 /$. In contrast, it has been reported that the morphology and distribution of precipitates have some influence on the hot ductility of microalloyed steels $/ 2 /$. The change of precipitates in terms of the size and morphology will alter the total area of the matrix/precipitate interface associated with the interfacial tension in the presence of stress. However, in the present study, it would be very difficult to estimate the influence of the morphology change of the precipitate, because the volume of precipitates was quite different in both the as-cast and solution treated samples.

\subsection{Influence of grain size on hot ductility}

For the tensile test results of the ST-2 and ST-5 samples, it is possible to isolate the influence of grain size from that of precipitation because of the similar amount of precipitation before testing (Figure 2). The results demonstrate that the enlargement in grain size induces a decrease of the RA values with test temperature (Figure 5). There is a small effect of a decrease in grain boundary area on the hot ductility at lower and higher temperatures in the test temperature range of 950 to $1200^{\circ} \mathrm{C}$. These results imply that grain size has little or no influence on the hot deformation of alloy C-276 ESR materials, when grain boundary sliding and dynamic recrystallization are the main deformation mechanisms until fracture occurs (Figures 10 and 11). On the other hand, the enlargement in grain size has a detrimental but small influence on hot ductility at intermediate temperatures of 1050 and $1100^{\circ} \mathrm{C}$ where the effect of precipitates dominates to produce a cleavage failure (Figure 6). These results can be explained by the precipitate volume fraction in relation to the grain boundary area during deformation. It is considered that the enlargement in grain size will cause an increase of the precipitate fraction on the grain boundaries even if the total area fraction of precipitates appears to be constant (Figure 2). This feature is the main reason for the ductility decrease and its expanded temperature range. (Figure 5). Therefore, it is suggested that the lowest hot ductility occurs at intermediate temperatures when an extensive solution of precipitates and the enlargement in grain size are generated by solution treatment for 5 hours and there is reprecipitation in a fine form at the grain boundaries and within the matrix before testing.

Figure 13 shows the correlation of hot ductility and grain size of alloy C-276 ESR ingots in the temperature range of 950 to $1200^{\circ} \mathrm{C}$. The RA values appear to be somewhat dependent on the grain size and there is an irregular variation in hot ductility with grain size. However, hot ductility in general shows a decreasing tendency with increasing grain size. These results indicate that a reduction in grain size would be more effective in improving hot ductility if the effect of the precipitates dominates the fracture mechanism, because an enlarged grain boundary area will favour both grain boundary sliding during deformation and a decrease of the precipitate fraction.

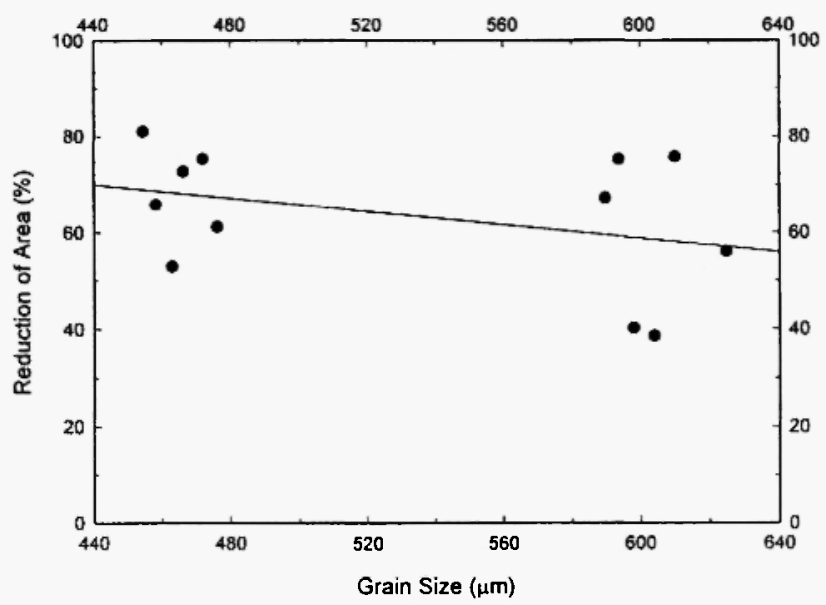

Fig. 13: The correlation of hot ductility and grain size in alloy C-276 ESR ingot.

\subsection{Hot ductility decreases of solution treated alloy C-276}

In the ST-2 and ST-5 samples, it was observed that there were noticeable ductility decreases in the intermediate temperature range around $1050^{\circ} \mathrm{C}$ and at the highest temperature $\left(1200{ }^{\circ} \mathrm{C}\right.$ in the present study). The ductility decreases reduced the temperature range available for hot deformation. The decreases result from not only an enlargement in grain size, but the 
reprecipitation at grain boundaries and also within the grains before deformation (Figures 2 and 3). During solution treatment for a maximum of 2 hours, most of the precipitates dissolve. However, before testing, especially at intermediate test temperatures, small amounts of reprecipitation occur during the heating/holding time periods. This fact implies that the heating cycle for tensile tests, especially at the intermediate temperatures in the present study, can possibly allow reprecipitation at the grain boundaries. Through a metallographic examination of the samples tested at intermediate temperatures, the ductility results appear to be intimately associated with reprecipitation.

Figure 14 shows the fracture surface of the ST-2 sample tested at $1050^{\circ} \mathrm{C}$. It can be seen that the precipitates in the grain boundaries are responsible for the intergranular fracture, which controls the decrease of hot ductility. These precipitates are not likely to be from reprecipitation during deformation, because of the fast strain rate $(6.1 / \mathrm{sec})$ in the present study. The precipitation in the grain boundary would offer a source for crack initiation and propagation, leading to cleavage failure. Thus precipitates at the grain boundary would prevent dynamic recrystallization from occurring, encourage crack linkage and would also be expected to favour intergranular failure during tensile deformation. As a consequence, the precipitates, especially at the grain boundaries and even at high temperatures, would have been sufficient to delay the onset of dynamic recrystallization until a fracture had occurred, giving

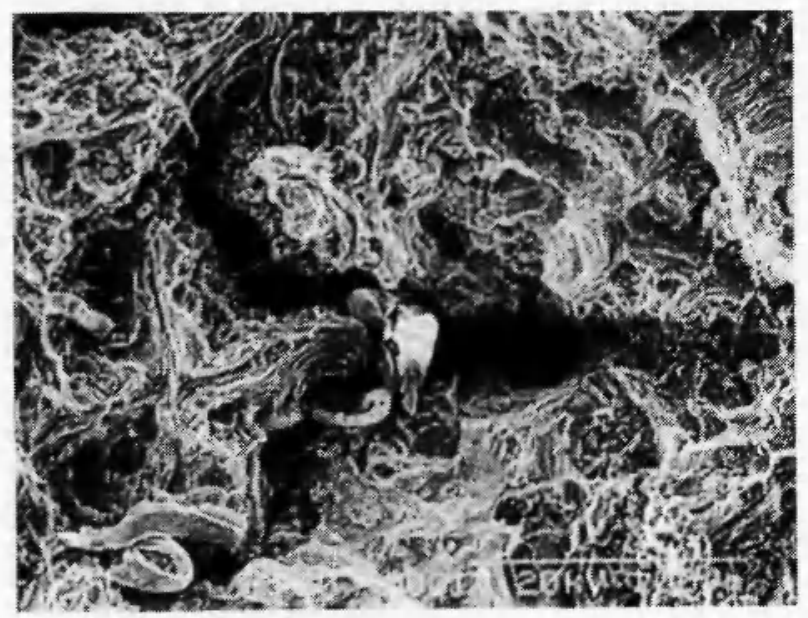

Fig. 14. Fracture surface of ST-2 sample tested at $1050^{\circ} \mathrm{C}$. rise to low ductility.

Figure 15 shows the microstructure in the vicinity of the failure in the longitudinal section of the ST-2 sample tested at $1200^{\circ} \mathrm{C}$. It is observed that dynamic recrystallization was generated during deformation and that fractures occurred along these new grain boundaries. As there is no evidance of fractures caused by precipitates in the grain boundaries, the decrease in hot ductility at this temperature is probably the result of grain boundary weakening during high temperature deformation.

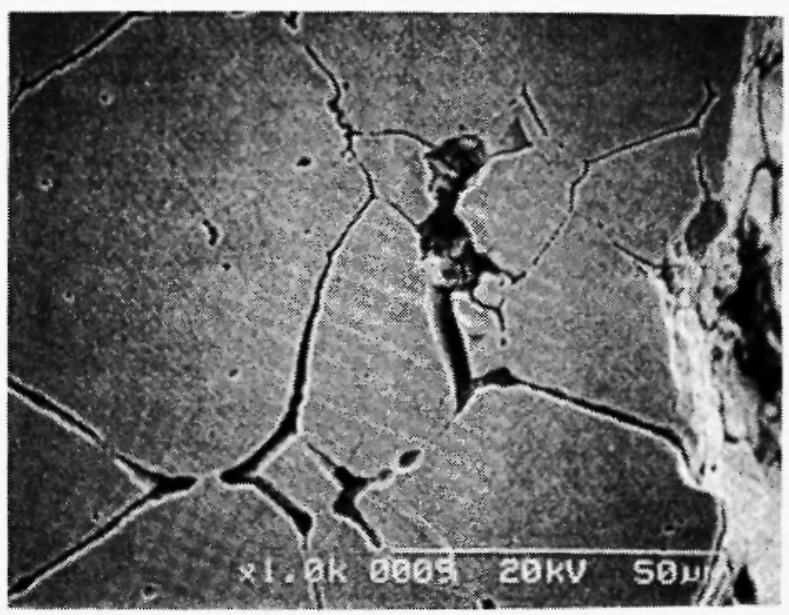

Fig. 15: Microstructure in the vicinity of the longitudinal section of the ST-2 sample tested at $1200^{\circ} \mathrm{C}$.

From these results, it is possible to predict that a fast heating rate and prompt deformation at given temperatures of less than $1200^{\circ} \mathrm{C}$ would be better with respect to hot deformation in $\mathrm{C}-276$. This procedure could avoid the hot ductility decrease at intermediate temperatures caused by reprecipitation before deformation.

\subsection{Correlation of the influence of precipitation and grain size}

Figure 16 shows the correlation of the influence of precipitate volume fraction and grain size on hot ductility at 950,1050 and $1150^{\circ} \mathrm{C}$. It can be observed that the RA values are closely associated with the precipitate fraction at 950 and $1150^{\circ} \mathrm{C}$. Except at 


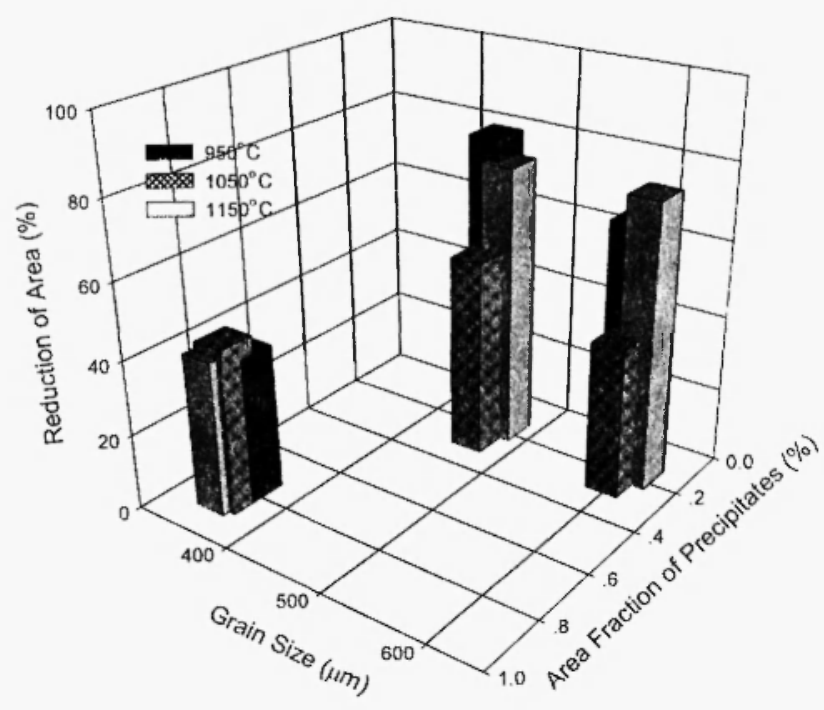

Fig. 16: The correlation of influence of precipitate amount and grain size on the hot ductility of alloy C-276 ESR ingot at 950, 1050 and $1150^{\circ} \mathrm{C}$

$1050^{\circ} \mathrm{C}$, the hot ductility of $\mathrm{C}-276$ tends to be in inverse proportion to the amount of precipitates. In particular, hot ductility always shows RA values less than $50 \%$ at any test temperature if the values of the area fraction precipitate are greater than $0.6 \%$. These effects could be mainly attributed to the detrimental influence of the TCP phase on hot ductility. With respect to grain size, the RA values are over $60 \%$ at 950 and $1150^{\circ} \mathrm{C}$ if the grain size is greater than $400 \mu \mathrm{m}$ in the transverse section of the ESR ingots. However, these excellent hot ductility values are principally attributed to the elimination of precipitates.

Thus, the hot ductility results in general indicate that the hot ductility of C-276 is mainly dominated by the precipitation of $\mathrm{P}$ phase which forms at the grain boundary. Grain size has a minor influence on hot ductility only if the effect of precipitates dominates in producing an intergranular failure at around $1050^{\circ} \mathrm{C}$. It is found that $\mathrm{RA}$ values greater than $60 \%$ (implying excellent hot ductility) have been achieved at 950 and $1150^{\circ} \mathrm{C}$ only if the area fraction of the precipitates is less than $0.4 \%$.

\section{CONCLUSIONS}

In the present study, the influence of precipitation and grain size on the hot ductility of ESR ingots of alloy C-276 has been determined at a strain rate of $6.1 / \mathrm{sec}$. The following conclusions are drawn;

1) The precipitation of $P$ phase has a significant influence on the hot ductiltiy in the longitudinal direction of the alloy C-276 ESR ingots in the temperature range of 950 to $1200{ }^{\circ} \mathrm{C}$, since these precipitates within the grains and grain boundaries tend to fracture prior to grain boundary sliding and dynamic recrystallization during deformation, hence favoring a low-ductility cleavage fracture.

2) Almost complete dissolution of precipitates appears to be very effective in improving hot ductility, giving grain boundary sliding at below $1000^{\circ} \mathrm{C}$ and dynamic recrystallization at above $1100^{\circ} \mathrm{C}$. However, there are hot ductility decreases in the solution treated samples at around 1050 and $1200^{\circ} \mathrm{C}$. A significant ductility decrease at around $1050^{\circ} \mathrm{C}$ is attributed to re-precipitation before deformation, which is responsible to grain boundary weakening and intergranular failure. The slight ductility drop at $1200^{\circ} \mathrm{C}$ is caused by grain boundary weakening at high temperatures.

3) The enlargement in grain size reveals none or only a slight influence on hot ductility when considerable dissolution of the precipitates by solution treatment is attributed to grain boundary sliding and dynamic recrystallization during deformation. However, there is a detrimental effect on hot ductility where the effect of grain boundary precipitates dominates and prevents dynamic recrystallization at $1050^{\circ} \mathrm{C}$, hence producing an intergranular fracture.

4) The hot ductility results indicate that the hot ductility behaviour of alloy C-276 is mainly dominated by the volume of precipitate which forms at the grain boundaries and within the grains. The grain size has a minor influence on hot ductility when hot ductility is mainly determined by the effect of the precipitates. 


\section{REFERENCES}

1. B. Mintz, M. Shaker and D.N. Crowther, Mater. Sci. Technol., 13, 243 (1997).

2. D.N. Crowther and B. Mintz, Mater. Sci. Technol., 2, 1099 (1986).

3. D.N. Crowther and B. Mintz, Mater. Sci. Technol. 2, 951 (1986).

4. K. Yamanaka, F. Terasaki, H. Ohtani, M. Oda and M. Yoshihara, Trans. Iron Steel Inst. Jpn., 20, 810 (1980).

5. Y. Gao and K. Sorimachi, ISIJ Int., 35, 914 (1995).

6. C.F. Jr. Hickey and A.A. Anctil, J. Heat Treat., 4, 177 (1985).

7. R.G. Thompson and S. Genculu, Weld. J., 62, 337s (1983).

8. K. Yasumoto, Y. Maehara, S. Ura and Y. Ohmori, Mater. Sci. Technol., 1, 111 (1985).

9. C.Ouchi and K.Matsumoto, Trans. Iron Steel Inst. Jpn., 22, 181 (1982).

10. Alloy Digest, Apr., 2 (1999).

11. M.J. Cieslak, T.J. Headley, and A.D. Romig, Jr, Metall. Trans. A, 17A, 2035 (1986).

12. M. Rockel and W. Herda, Stainless Steel World, 8, 43 (1996).

13. D.C. Agarwal, U. Heubner, and W.R. Herda, Corrosion Review, 12, 275 (1994).

14. G. Hoyle, Electroslag Processes-Principles and Practices, London, Applied Science Publihsers 1983.

15. B.I. Medovar and G.A. Boyko, Electroslag Technology, Springer-Verlag, New York Inc., New York, 1991.

16. T.K. Kim, J. Jang, H.W. Kwon and S.S. Kim, $J$. Kor. Inst. Met. \& Mater., 35, 57 (1997) .
17. R.G. Baligidad, U. Prakash, V.R. RaO, P.K. Rao, and N.B. Ballal, Ironmaking and Steelmaking, 21, 324 .(1994).

18. M. Chatterjee, M.S.N. Balasubramanian, K.M. Grpt, and P.K. Rao, Ironmaking and Steelmaking, 21, 399 (1994).

19. J.W. Pridgeon, M.L. Pochon, R.T. Gross and V. Sharma, Conf. Trans. Vac. Met., Am. Vac. Soc., New York, .525 (1968).

20. A. Mitchell, F.R. Carmona, and Wei Chi-Ho, Iron Steelmaker, 9, 37 (1982).

21. F.Reyes-Carmona and A. Mitchell, ISIJ. Int., 32, 529 (1992).

22. A. Mitchell, F. Reyes-Carmon, and E. Samaelsson, Trans. Iron Steel Inst. Jpn., 24, 547 (1984). .

23. D.P. Shoemaker, C.B. Shoemaker, and F.C. Wilson, Acta Cryst. 10, 1 (1957).

24. H.T. Beattie, Jr. and W.C. Hagel, Trans. Met. Soc. Met., 233, 277 (1965).

25. R.B. Leonard, Corrosion, 25, 222 (1969).

26. M. Raghavan, B.J. Berkowitz, and J.C. Scanlon, Met. Trans. A, 13A, 979 (1982).

27. M.J. Cieslak, G.A. Knorovsky, T.J. Headley, and A.D. Romig, Jr., Met. Trans. A, 17A, 2107 (1986).

28. M.A. Streicher, Corrosion, 32, 79 (1976).

29. D.S. Bloom and N.J. Grant, Trans. AIME. Feb., 261 (1954).

30. M. Raghavan, R.R. Mueller, G.A. Vaughn, and S. Floreen, Met. Trans. A, 15A, 783 (1984).

31. S.T. Wlodek, Trans. Am. Soc. Met., 57, 110 (1964)

32. E.W. Ross, J. Metals, 19, 12 (1967).

33. C.T. Sims, J. Metals, 18, 1119 (1966).

34. R. Vincent, Acta Metall., 33, 1205 (1985).

35. S.T. Wlodek, Trans. Am. Soc.Met., 56, 287 (1963). 